\title{
Polymer Nanocomposites as Insulation for HV DC Cables - Investigations on the Thermal Breakdown
}

\author{
Ch. Chakradhar Reddy and T. S. Ramu \\ Department of Electrical Engineering \\ Indian Institute of Science \\ Bangalore, 560 012, India.
}

\begin{abstract}
With the advent of nano-particle fillers in insulating materials, the insulating materials of superior quality have come to fore. In the recent past, nanocomposite LDPE/XLPE (Low Density Polyethylene/Cross Linked Polyethelene) power cable dielectrics have been synthesized. A preliminary evaluation of these new class of materials seem to show that, addition of small amounts of sub-micron inorganic fillers improved the dielectric properties of the composite, in particular, the volume resistivity, and the dc breakdown strength. The thermal behaviour, for example, the stability of composites against decomposition and ensuing electrical failure, do not seem to have been addressed. In a conventional XLPE insulated cable, the average thermal breakdown strength and maximum temperature at the onset of breakdown were seen to be markedly lower than the corresponding intrinsic breakdown strength and decomposition temperature. In the present paper, the Authors have presented and demonstrated the methods of estimating the limiting thermal breakdown voltages on a few nanocomposite materials used as power cable insulation. Experimental data on the volume resistivity reported in recent literature has been used in the series of computations. Nanocomposites of LDPE doped with small amounts of nano-particles of $\mathrm{MgO}$, are chosen. The results show a considerable improvement in the thermal maximum voltage and other related parameters.
\end{abstract}

Index Terms: - polymer nanocomposite, LDPE, insulation, HV DC cable, thermal stability, de conductivity, $\mathrm{MgO}$ filler

\section{INTRODUCTION}

POLYMER nanocomposites are thought to be the state of the art dielectric materials of improved electrical performance [1-7]. Recent studies [8-14] have shown that LDPE and XLPE filled with a small amount of inorganic filler, $\mathrm{MgO}$, hold great promise as power cable insulation.

Use of polymer insulation, such as XLPE for high voltage (HV) ac cables for voltages of $500 \mathrm{kV}$ and beyond is well-proven. As for HVDC cable application XLPE and similar polymeric insulation, for voltages $>500 \mathrm{kV}$, is still in an experimental stage [8-10]. Among others, the more important problems which preclude use of these dielectrics, are, stress inversion, a possible thermal failure in the insulation, and space charge accumulation, which are particularly relevant in dc applications. In an effort to offset these problems, it was discovered that addition of inorganic fillers in a class of polymers mentioned above could offer a solution.

In the early developmental chronology of HVDC extruded cable, attempts were made, by certain research groups [8-14] to

Manuscript received on 11 June 2007, in final form 19 September 2007. employ mineral filler. Approximately $40 \mathrm{wt} \%$ of the filler in XLPE seemed to give some improvement in dc breakdown voltage, however, the impulse breakdown strength was reportedly reduced by this addition. In a compulsion to improve the impulse breakdown strength, inorganic fillers, $\mathrm{MgO}, \mathrm{SiO}_{2}$ and $\mathrm{Al}_{2} \mathrm{O}_{3}$ were tried out. The thermally simulated current (TSC) studies of these filled polymers indicated that, by and large, $\mathrm{MgO}$ as the best possible filler in view of the minimal space charge accumulation.

Inorganic nano-MgO particles, in XLPE/LDPE have shown considerable improvements in dc as well as impulse breakdown voltages in addition to desirable significant improvement in volume resistivity. Taking this clue from the published literature the authors of this paper investigated the thermal breakdown limits of these nanocomposite materials.

The steady state maximum thermal voltage (MTV), also called the thermal breakdown voltage, of a dielectric specimen, as per Whitehead and O'Dwyer [15, 16], was defined to be the maximum voltage that can be applied across the specimen such that no thermal breakdown could ever take place, theoretically, even after infinite time of application of voltage. For a voltage of value less than this there can never 
be a thermal breakdown. However, it so happens that, a few percentage higher value of voltage than this could result in breakdown within a finite time.

In their earlier works $[17,18]$, the authors have shown that the maximum thermal voltage assumes particular importance in dc cables. The fact that the MTV is geometry specific, in that, in the cylindrical geometry, the heat needs to escape only through the outer boundary, makes the MTV lesser than in plane parallel geometry. Furthermore, the MTV decreases with Ohmic losses in the conductor. Also, multifactor stress dependence of dc conductivity is seen to give rise to a positive feedback effect to the heat dissipation process, resulting in a thermal runaway. More often, it was also found that the theoretical thermal breakdown strengths are considerably lower than the experimental dc breakdown strengths.

Using the authors' theory and experimental data on volume resistivity of the MgO-LDPE nanocomposites available in the literature [12-14], the thermal performance of the cable insulation has been studied. In line with the exhibited trends in dc breakdown strengths reported earlier, the addition of nanosize $\mathrm{MgO}$ filler is shown to improve the thermal breakdown voltage until around $5 \mathrm{phr}(1 \mathrm{phr}: 1 \mathrm{~g}$ of $\mathrm{MgO}$ added to $100 \mathrm{~g}$ LDPE).

\section{EXPERIMENTAL DETAILS}

The details of nanocomposite sheet specimens containing different filler concentrations are included in Table 1 [12-14] for a quick reference. Energy Dispersive X-ray fluorescence (EDX) and transmission electron microscope (TEM) images taken from different parts of specimen, indicated, that $\mathrm{MgO}$ particles of diameter $200 \mathrm{~nm}$ or less were nearly uniformly dispersed in LDPE matrix and that the mean diameter of the particle was about $50 \mathrm{~nm}$. In MgO-LDPE composites, the volume resistivity $(\rho)$ was found to increase with $\mathrm{MgO}$ content up to a concentration of $5 \mathrm{phr}$, beyond this value, a reduction in $\rho$ has been reported. For instance, with $1 \mathrm{phr}$ $\mathrm{MgO}$ content an increment of $\rho$ by an order of 10 was observed at $90^{\circ} \mathrm{C}$ and $80 \mathrm{kV} / \mathrm{mm}$.

Table 1. Details of nanocomposite dielectrics [12-14].

\begin{tabular}{|l|l|}
\hline Base polymer & LDPE \\
\hline Filler & $\mathrm{MgO}-$ Nanoparticles \\
\hline Filler concentrations $(\mathrm{phr})$ & $0,1,5$ and 10 \\
\hline Dielectric thickness & $200 \mu \mathrm{m}$ \\
\hline Surface treatment on filler & Silane treated \\
\hline Test temperatures & 25,60, and $90{ }^{\circ} \mathrm{C}$ \\
\hline Test stresses $(\mathrm{kV} / \mathrm{mm})$ & $20,40,60$ and 80 \\
\hline
\end{tabular}

\section{THEORETICAL ASPECTS}

For the sake of completeness and for a quick reference, the theory of thermal breakdown in cables and other related aspects relevant to the paper are provided in brief in the following.

\subsection{SOLUTIONS OF THE BOUNDARY VALUE PROBLEM}

Among the several models for dc conductivity in dielectrics, the following is found to be one of the best suited representations.

$$
\sigma=A \times e^{\left(a|E|-\frac{b}{T}\right)}
$$

where, the parameters, $a$ and $b$ are respectively, the stress and temperature coefficients. $A$ is a material related constant, $E$ is the Electric Field $(\mathrm{V} / \mathrm{m}), T$ the Temperature $(\mathrm{K})$, and $\sigma$ the dc conductivity.

The steady state temperature and the steady state electric field in the body of the insulation, $r_{1}<r<r_{2}$, Figure 1, are given by [15];

$$
T(r)=a_{1} I_{0}(2 \sqrt{\beta r})+a_{2} K_{0}(2 \sqrt{\beta r})+\frac{\alpha}{\beta}-\frac{\gamma}{\beta} \ln (r)
$$

and

$$
E(r)=\frac{-c_{2}}{2 c_{1}} \pm \sqrt{\frac{c_{2}^{2}}{4 c_{1}^{2}}-\frac{1}{c_{1}}\left(\ln \left(\frac{I}{2 \pi r A E_{0}}\right)+\frac{b}{T(r)}+\frac{3}{2}\right)}
$$

where, $a_{1}$ and $a_{2}$ are arbitrary constants to be determined by the boundary conditions, $I_{o}$ and $K_{o}$ are the modified Bessel's functions of zero order, $\alpha, \beta, \gamma, E_{o}, c_{1}$ and $c_{2}$ are other constants [17], dependent on, the dc conductivity coefficients, the thermal conductivity $(k)$ and the insulation leakage current $(I)$.

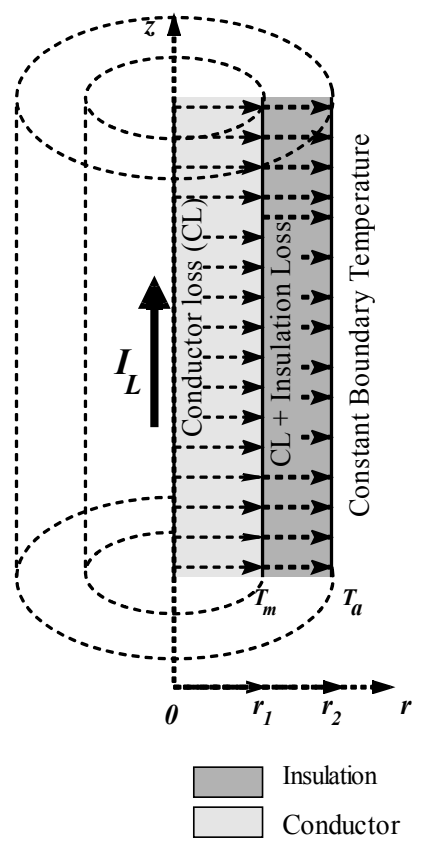

Figure 1. Heat flow patterns in a dc cable (dotted arrows).

Also, if the sheath temperature is $T_{s}$ the MTV of cable dielectric was shown to be [18];

$$
V_{m}^{2}=V_{m U}^{2}-2 I_{L}^{2} R_{c} R_{i c}
$$


where;

$V_{m} \quad$ is the MTV of the cable under loaded condition

$V_{m U}$ is the MTV of the cable under no load, given below

$I_{L} \quad$ is the load current

$R_{c} \quad$ is the conductor resistance per unit length

$R_{i c} \quad$ is the critical insulation resistance, given below

$$
V_{m U}^{2}=\int_{T_{s}}^{\theta} \frac{2 k}{\sigma} d T
$$

and

$$
R_{i c}=\frac{1}{2 \pi} \int_{r_{1}}^{r_{2}} \frac{1}{r \sigma} d r
$$

Also for a dielectric placed in the parallel plane electrode geometry, the MTV is given by [18];

$$
V_{m}^{2}=\int_{T_{s}}^{\theta} \frac{8 k}{\sigma} d T
$$

The $\theta$, appearing in equations (5) and (7), is the value of maximum insulation temperature at the inception of thermal breakdown. In a dc cable the maximum insulation temperature normally occurs at $r=r_{l}$ and in plane parallel geometry it occurs at the middle of the insulation. Detailed investigations on $\theta$ including computation of $\theta$ are presented in [18].

\subsection{THE IMPORTANCE OF MTV}

Among others, the thermal breakdown assumes particular importance in a dc cable because of the following reasons:

- The MTV of cable insulation, even under no load conditions, is considerably less than that of an equivalent thick insulating slab of plane parallel geometry with boundaries exposed to ambient. In loaded conditions a further decrement in MTV is expected. External conditions surrounding the cable also affect the MTV $[17,18]$

- The times to thermal breakdown being dependent on incremental voltage higher than MTV, accurate laboratory prediction is hindered by indefinite time requirement. Also, the initial processes are so innocuous that a possible failure (or runaway), for example, after a year, cannot be predicted till a time few hours/seconds before breakdown, depicted in Figure 2.

It has been said earlier that, in the recent past, it was seen that nano particles of a class of inorganic oxides fillers, such as $\mathrm{MgO}$, added to organic polymers such as polyethylene in minute quantities improved the electrical performance of the composite material. The authors considered the aspects of thermal breakdown of these composites on a theoretical basis to check if these composites can improve their thermal performance as applicable to the dc cables.

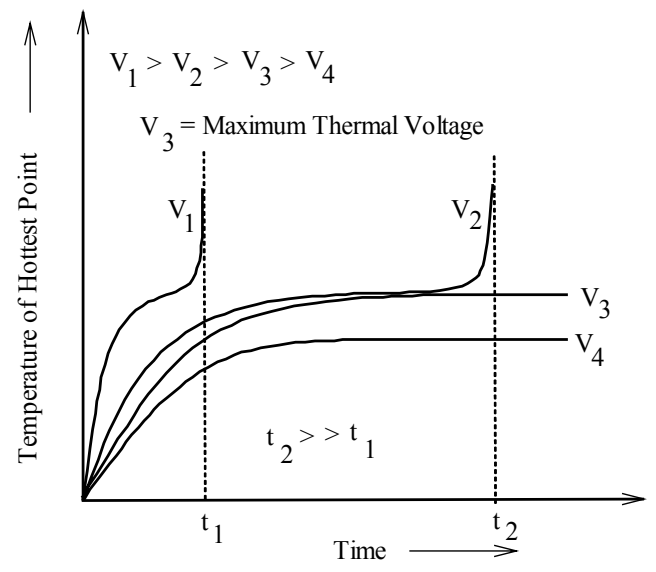

Figure 2. Depicting times to thermal runaway in the cable insulation (Arbitrary units)

\section{RESULTS AND DISCUSSION}

The nano composite dielectrics, both in cylindrical and in plane-parallel geometry, are considered. In order to establish relative equivalence between the two geometries, and also among all the cases considered, the exposed-boundary temperatures are appropriately adjusted. This means the boundaries, which are exposed to ambient or surroundings, are taken to be at a constant known temperature. Also, unless otherwise stated, the computations hear after correspond to the 'steady state'.

Table 2 includes the computed model parameters of the dc conductivity $(\sigma)$ of LDPE-MgO nanocomposites. Figures, 3 and 4 show, respectively, the volume resistivity $(1 / \sigma)$ with stress and inverse temperature. The lines (dotted, dashed or solid) are computed using equation (1) with their respective model parameters (Table 2) for different filler concentrations.

Table 2. Computed conductivity coefficients of nanocomposites.

\begin{tabular}{|c|c|c|c|c|}
\hline Coefficient & LDPE & $\begin{array}{c}\text { LDPE+ } \\
1 \mathrm{phr} \mathrm{MgO}\end{array}$ & $\begin{array}{c}\text { LDPE+ } \\
5 \mathrm{phr} \mathrm{MgO}\end{array}$ & $\begin{array}{c}\text { LDPE+ } \\
10 \mathrm{phr} \mathrm{MgO}\end{array}$ \\
\hline$b(\mathrm{~K})$ & 9234 & 9459 & 10027 & 9076 \\
\hline$a(\mathrm{~mm} / \mathrm{kV})$ & 0.0498 & 0.0645 & 0.0619 & 0.0703 \\
\hline$A(\mathrm{~S}) \times 10^{-3}$ & 0.8315 & 0.0328 & 0.0337 & 0.0015 \\
\hline $\begin{array}{l}b / a \times 10^{11} \\
\left(\mathrm{kV}{ }^{\circ} \mathrm{K} / \mathrm{mm}\right)\end{array}$ & 1.8542 & 1.4665 & 1.6199 & 1.2910 \\
\hline
\end{tabular}

\subsection{THE CYLINDRICAL GEOMETRY (CABLES)}

The Table 3 includes the geometrical and other parameters used for computations in the cylindrical geometry. In the following, the steady state stress and temperature distributions, the steady state thermal breakdown strength and the steady state maximum thermal voltages of the nanocomposites, are investigated. 
Table 3. Parameters of the Cables.

\begin{tabular}{|c|c|}
\hline Parameter & Value \\
\hline$r_{1}$ & $22.5 \mathrm{~mm}$ \\
\hline$r_{2}$ & $31.5 \mathrm{~mm}$ \\
\hline$R_{c}$ & $17.38 \mu \Omega / \mathrm{m}$ \\
\hline$k$ & $0.34 \mathrm{~W} / \mathrm{m} \mathrm{K}$ \\
\hline
\end{tabular}

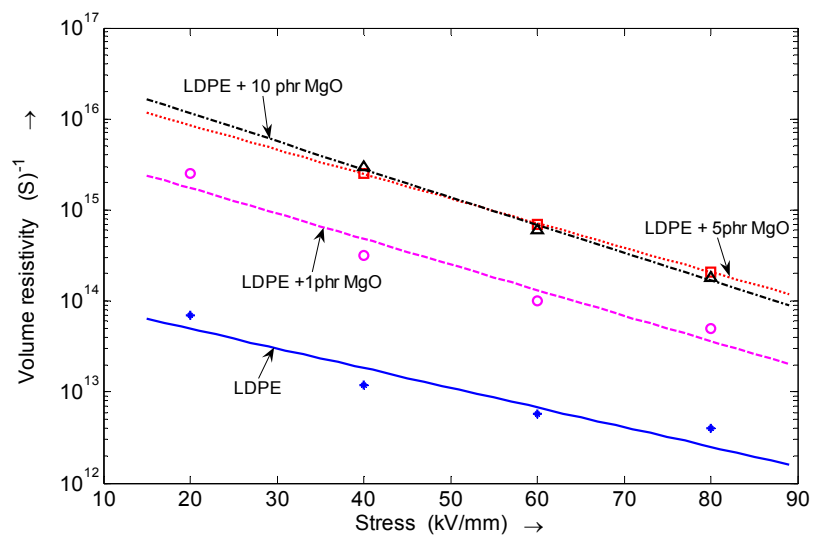

Figure 3. Volume resistivity $(1 / \sigma)$ vs stress of the specimen with different filler concentrations, showing experimental data points and a fit to the data (the lines) using equation (1)

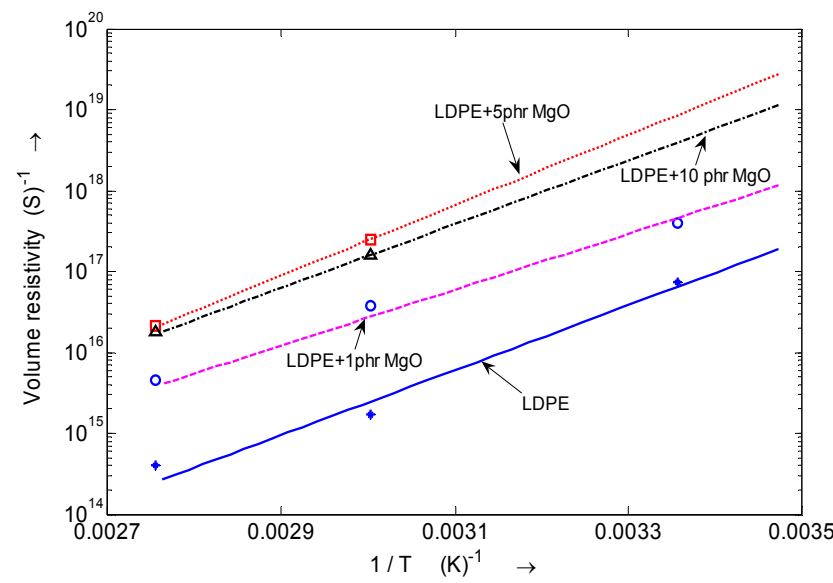

Figure 4. Volume resistivity $(1 / \sigma)$ vs inverse of absolute temperature of the specimen with different filler concentrations, showing experimental data points and a fit to the data (the lines) using equation (1).

\subsubsection{THE STRESS AND TEMPERATURE DISTRIBUTIONS}

Figures 5 and 6, depict the steady state stress and temperature distributions (computed using equations (2) and (3)), for $1 \mathrm{phr}$ MgO-LDPE cable. It may be noted that the addition of nano-size $\mathrm{MgO}$ filler has not altered the nature of the solutions (double solutions at a given voltage: a stable and an unstable solution) of the continuous phase problem discussed in [17] and that, the nature of solutions seem to remain invariant with respect to the content of $\mathrm{MgO}$. Also, it can be observed that, for voltage values greater than the MTV, steady state solutions do not exist, implying a thermal runaway.

\subsubsection{Effect of Filler Concentration on the Thermal Breakdown}

Figures 7 and 8 respectively show the maximum stress and temperature, computed using equations 2 and 3 , for the four cables ( $0 \mathrm{phr}, 1 \mathrm{phr}, 5 \mathrm{phr}$ and $10 \mathrm{phr}$ MgO filled LDPE). A careful observation reveals that up to $5 \mathrm{phr}$ the curves tend to shift to right implying an improvement in stability, while the trend gets reversed beyond $5 \mathrm{phr}$ as for $10 \mathrm{phr}$ the curves have shifted left.

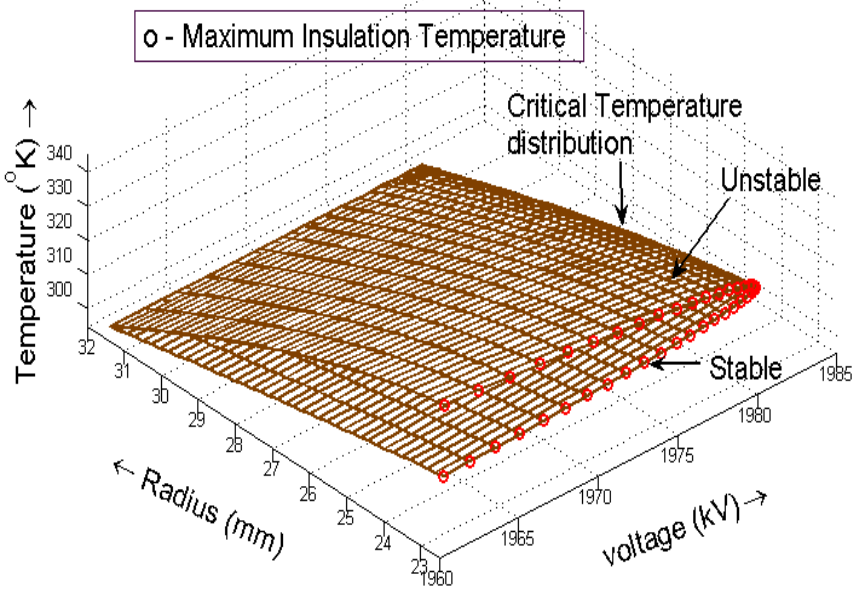

Figure 5. A 3-dimensional view of envelope of temperature distribution for 1 phr MgO-LDPE nanocomposite cable (at $\left.I_{L}=1400 \mathrm{~A}, T_{s}=25^{\circ} \mathrm{C}\right)$.

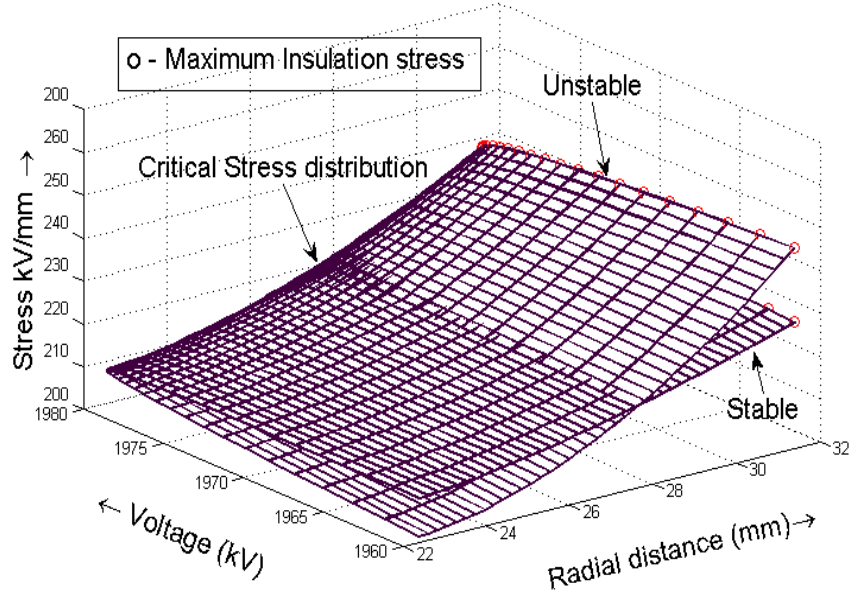

Figure 6. A 3-dimensional view of envelope of stress distribution for $1 \mathrm{phr}$ MgO-LDPE nanocomposite cable (at $I_{L}=1400 \mathrm{~A}, T_{s}=25^{\circ} \mathrm{C}$ ).

The average thermal breakdown strength (thermal maximum voltage/insulation thickness) for the four cables and the maximum insulation field at breakdown are plotted in the Figure 9. As can be seen from this figure, when the nano-particle content exceeds $5 \mathrm{phr}$ there is a systematic reduction in the maximum and mean thermal breakdown strengths. The Author's like to point out that similar observations have been made in so far as the volume resistivity is concerned. 


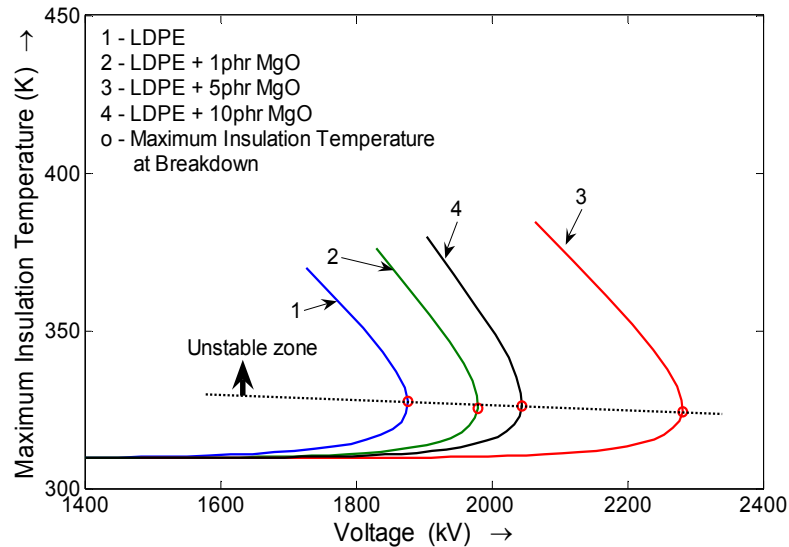

Figure 7. Maximum Insulation Temperature vs Voltage for all the four nanocomposite cables.

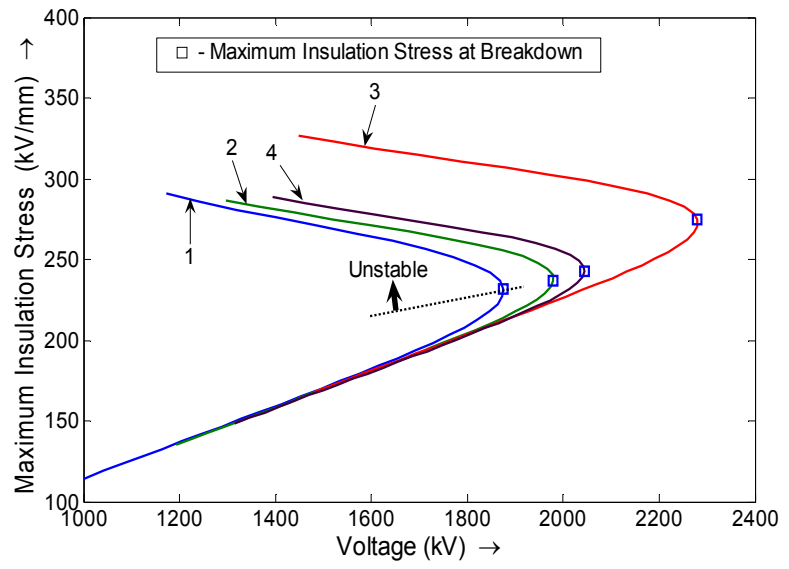

Figure 8. Maximum Insulation Stress vs Voltage for all the four nanocomposite cables (the curves follow the same legend as in Figure 7).

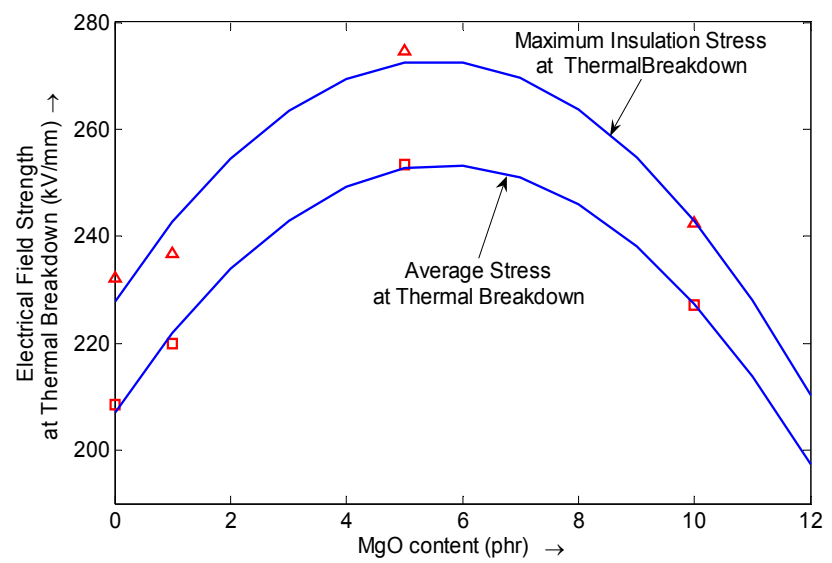

Figure 9. Average and maximum insulation stress of the nanocomposite cables at thermal breakdown $\left(I_{L}=1400 \mathrm{~A}, T_{s}=25^{\circ} \mathrm{C}\right)$

The form of the breakdown voltage profile suggests that a least square polynomial fit for the breakdown voltages can be worked out. In the following, a least squares polynomial regression equation for the average breakdown strength (with $I_{L}=1400 \mathrm{~A}, T_{s}=25^{\circ} \mathrm{C}$ ) has been suggested.

$$
E_{\text {bdavg }}(x)=207.06+16.22 x-1.42 x^{2}
$$

where, $E_{\text {bdavg }}(x)$ is the average thermal breakdown strength $(\mathrm{kV} / \mathrm{mm})$ at a filler concentration of $x \mathrm{phr}$. With this fit, the maximum breakdown strength can be shown to occur, at a filler concentration of $x=5.7 \mathrm{phr}$.

Referring to Figure 7, it can be seen that the maximum insulation temperature at breakdown did not change significantly. The deviation of maximum insulation temperature at breakdown from the corresponding logarithmic estimate [18] is about $20{ }^{\circ} \mathrm{C}$.

A survey of the literature suggests that the thermal conductivity would also increase marginally with filler concentration [3, 19]. In such a case, a proportionate increment in MTV could be expected.

\subsubsection{Effect of Load Current on the MTV of Nanocomposites}

The dc cable is one of those cases where an external heat injection into the body of insulation needs a consideration. This heat injection results in a reduction in the MTV. The decrement, $\Delta V_{m}$ in MTV has been shown to be [18],

$$
\Delta V_{m}=\frac{I_{L}^{2} R_{c} R_{i c}}{V_{m U}}
$$

The thermal breakdown strength of the loaded dc cables, computed using equation (4) is presented in the Figure 10. It can be seen that the $5 \mathrm{phr}$ MgO-LDPE nanocomposite cable has highest breakdown strength at any load current. In spite of the differences in de conductivity, rate of reduction with load current (the slope of the curves) is found to be almost equal for all the nanocomposite cables, for the range of load currents considered. This can be understood, in the light of equation (9), where both the numerator and denominator increases with increased volume resistivity.

\subsection{MTV IN THE PARALLEL PLANE GEOMETRY}

The MTV in parallel plane electrode geometry is computed using equation (7). The effect of thickness on the average breakdown strength is presented in the Figure 11. As can be seen, for $1 \mathrm{phr} \mathrm{MgO}-\mathrm{LDPE}$ composite, the breakdown strength is lower compared to virgin LDPE, for the insulation thicknesses $<6 \mathrm{~mm}$. This behavior is possibly due to the differences in stress and temperature coefficients, for example the ratio, $b / a$, Table 2 , indicates a disproportionate increment in $a$ and $b$. For higher thickness, however, the breakdown strength increased for this content. At higher thickness the trend in breakdown strength tend to follow the trend of $b$ with $\mathrm{MgO}$ content.

The authors are investigating the possible interdependence of the coefficients $a$ and $b$ in the conductivity equation (1). It seems possible that the initial parts of the characteristics shown in Figure 11, (where, there is no similarity in the behaviour), can be explained based on the conductivity coefficients.

Referring to Figure 12, it may be observed that, in spite of the above fact that the breakdown strength is decreasing with 
thickness, the MTV is seen to increase with thickness. The rate of increase of MTV with thickness is higher in $5 \mathrm{phr}$ $\mathrm{MgO}-\mathrm{LDPE}$ composite. The reduction observed in breakdown strength of $1 \mathrm{phr}$ MgO-LDPE composite (for thickness $<6 \mathrm{~mm}$ ) has almost disappeared in MTV, due to the small multiplication factor, the thickness.

Similar computations can be made for cylindrical geometry also.

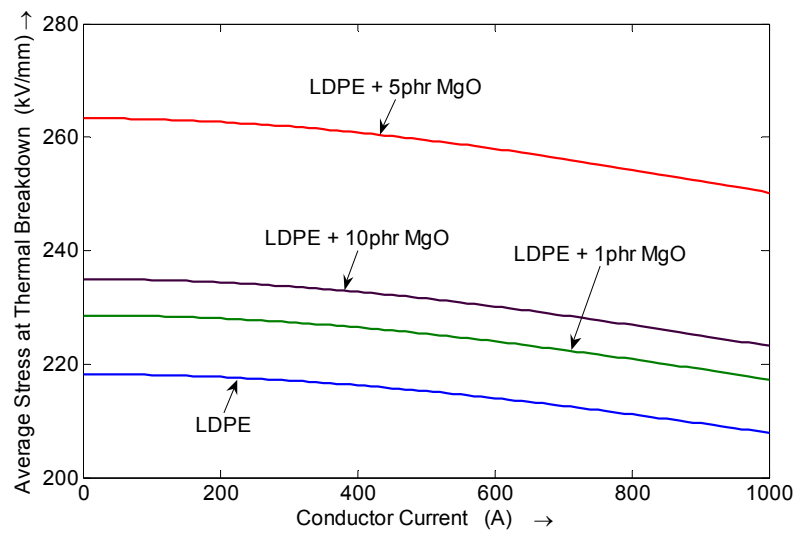

Figure 10. Average thermal breakdown strength of the nanocomposite cables with load current $\left(T_{s}=25^{\circ} \mathrm{C}\right)$

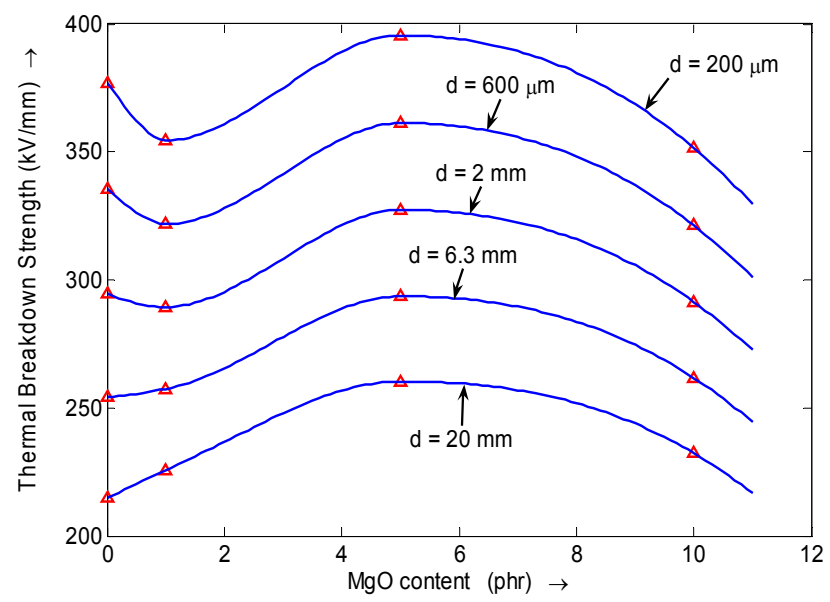

Figure 11. Average thermal breakdown strength of the nanocomposite in parallel plane geometry with thickness as a parameter $\left(T_{s}=25^{\circ} \mathrm{C}\right)$

\subsection{COMPARISON OF COMPUTED MTV WITH EXPERIMENTAL RESULTS}

Referring to Figure 13, the thermal breakdown strength (for $200 \mu \mathrm{m}$ insulation thickness corresponding to parallel plane geometry) can be seen to be about half of the experimental dc breakdown strength of their respective sheet specimen reported in [12-14]. It may be noted that, for higher thickness (Figure 11), as also for cables (Figures 9 and 10), a further reduction in breakdown strength is observed.

The initial trend in all these breakdown strengths is same, however, the $\mathrm{dc}$ and impulse strength seem to decrease marginally beyond $1 \mathrm{phr}$, while the thermal breakdown strength continued the trend till $5 \mathrm{phr}$, and then followed them for higher phr content.

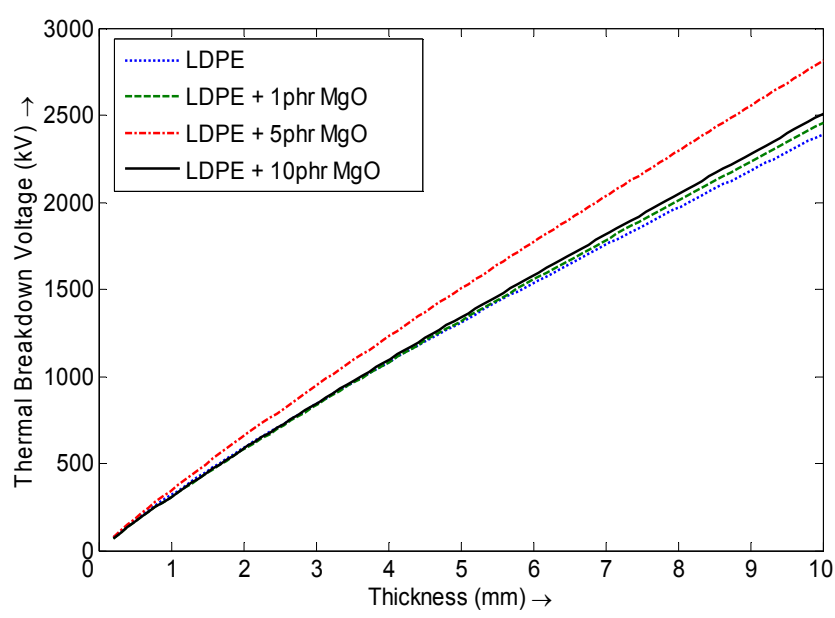

Figure 12. Thermal breakdown voltage of the nanocomposites in parallel plane geometry with thickness $\left(T_{s}=25^{\circ} \mathrm{C}\right)$

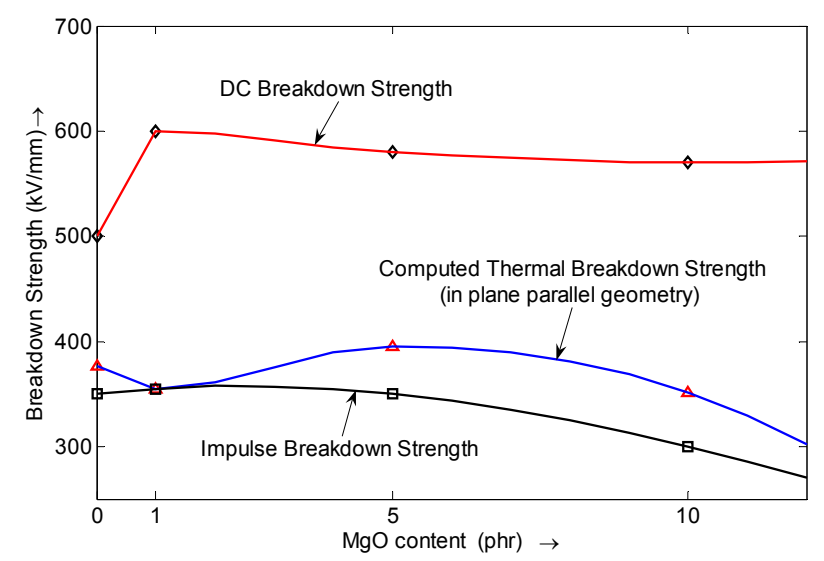

Figure 13. Comparison of authors' thermal breakdown strength in parallel plane geometry with experimental dc and impulse breakdown strengths.

\section{THE MULTI CORE MODEL AND THERMAL BREAKDOWN}

The recent proposal of multi core model, suggested by Tanaka et al $[1,2]$, can be extended to the thermal breakdown process. It is to be noted that the thermal breakdown is influenced by the thermal conductivity (heat transfer) and the dc conductivity (heat generation) of the insulation.

The proposal was discussed at length for high and low field conduction and it was believed that the 'third layer' along with the so called 'inter-filler collaborative effect' seem to contribute for the decrease in the dc conductivity. Introduction of deep traps are suggested with increased $\mathrm{MgO}$ content. The increment in thermal conductivity, on the other hand, was considered due to 'major contribution of the first layer' as well as 'inter-filler collaborative effect and the interfacial space charge' with increased $\mathrm{MgO}$ content.

However, the phenomenon associated with nanostructure, is still unclear and needs further consideration. For instance, the differences in stress and temperature coefficients of dc 
conductivity with filler concentration and as a result, the decrement in thermal breakdown voltage of $1 \mathrm{phr}$ composites for small thickness are being studied by the authors.

\section{CONCLUSIONS}

On the basis of the investigations carried out, among others, the following tangible conclusions can be drawn:

- The computed thermal breakdown strength of nanocomposite cables is shown to be less than the dc breakdown strength of corresponding planar specimen $(<50 \%$ of dc breakdown strength).

- For insulation thickness $>6 \mathrm{~mm}$, the thermal breakdown strength increases with filler concentration up to about $5 \mathrm{phr}$.

- Among the four nanocomposites, the LDPE with 5 phr nano-MgO has the highest thermal breakdown strength.

\section{ACKNOWLEDGEMENTS}

The authors gratefully acknowledge Yoshinao Murata (and his research group) for permitting the authors to use published data of their research work.

\section{APPENDIX}

Complete details concerning the parameters appearing in the equations (2) and (3) are available in [17], however, for a quick reference, certain important parameters are described below:

$$
\begin{aligned}
& \alpha=k_{1} b_{1} \\
& \beta=-k_{1} b_{3} \\
& \gamma=-k_{1} b_{2} \\
& k_{1}=I /(2 \pi k) \\
& c_{1}=1 /\left(2 E_{0}^{2}\right) \\
& c_{2}=-\left(2+a E_{0}\right) / E_{0} \\
& b_{1}=-b_{2}\left(\ln \left(\frac{I}{2 \pi A E_{0}}\right)+1+\frac{2 b}{T_{0}}\right) \\
& b_{2}=-\left(\frac{E_{0}}{a E_{0}+1}\right) \\
& b_{3}=b_{2} \frac{b}{T_{0}^{2}}
\end{aligned}
$$

\section{REFERENCES}

[1] T. Tanaka, "Dielectric Nanocomposites with Insulating properties", IEEE Trans. Dielectr. Electr. Insul, Vol. 12, pp. 914-928, 2005.

[2] T. Tanaka, M. Kazako, N. Fuse, Y. Ohki, "Proposal of a Multi-core Model for Polymer Nanocomposites”, IEEE Trans. Dielectr. Electr. Insul, Vol. 12, pp. 669-681, 2005.
[3] T. Tanaka, G. C. Montanari and R. Mulhaupt, "Polymer Nanocomposites as Dielectrics and Electrical Insulation - Perspectives for processing Technologies, Material Characterization and Future Applications", IEEE Trans. Dielectr. Electr. Insul, Vol. 11, pp. 763-784, 2004.

[4] T. J. Lewis, "Interfaces are the Dominant feature of Dielectrics at Nanometric Levels", IEEE Trans. Dielectr. Electr. Insul, Vol. 11, pp. 739753, 2004.

[5] T. J. Lewis, "Interfaces and Nanodielectrics are Synonymous", IEEE Trans. Dielectr. Electr. Insul, Vol. 1, pp. 812-825, 1994.

[6] J. K. Nelson, J. C. Fothergill, L. A. Dissado and W. Peasgood, "Towards an Understanding of Nanometric Dielectrics", IEEE Conf. Electr. Insul. Dielectr. Phenomena (CEIDP), pp. 295-298, 2002.

[7] J. K. Nelson, and Y. Hu, "Electrical Properties of $\mathrm{TiO}_{2}$ Nanocomposites", IEEE Conf. Electr. Insul. Dielectr. Phenomena (CEIDP), pp. 719-722, 2003.

[8] Y. Maekawa, A. Yamaguchi, C. Ikeda, Y. Sekii and M. Hara, "Research and Development of DC XLPE Cables", Proc. Jicable, B.9.3, pp.562-569, 1991

[9] Y. Maekawa, C. Watanabe, M. Asano, Y. Murata, S. Katakai and M. Shimada, "Development of 500kV XLPE Insulated DC Cable", Trans. IEE Japan, Vol. 121-B, No.3, pp.390-398, 2001 (in Japanese).

[10] Y. Maekawa, T. Yamanaka, T. Kimura, Y. Murata, S. Katakai and O. Matsunaga,"500kV XLPE Insulated DC Submarine Cable", The Hitachi Densen, No.2 1, pp.65-72, 2002, (in Japanese).

[11] K. Terashima, H. Suzuki, M. Hara and K. Watanabe, "Research and Development of $\pm 250 \mathrm{kV}$ DC XLPE Cable", IEEE Trans. Power Delivery, Vol.13, pp.7-16, 1998

[12] Y. Murata, Y. Murakami, M. Nemoto, Y. Sekiguchi, Y. Inoue, M. Kanaoka, N. Hozumi and M. Nagao, "Effects of Nano-sized MgO-filler on Electrical Phenomena under DC Voltage Application in LDPE", IEEE Conf. Electr. Insul. Dielectr. Phenomena (CEIDP), pp. 158-161, 2005.

[13] Y. Murata and M. Kanaoka, "Development History of HVDC Extruded Cable with Nanocomposite Material", 8th Intern. Conf. Properties and applications of Dielectric Materials (IEEE-CPADM), pp. 460-463, 2006.

[14] Y. Murata, Y. Sekiguchi, Y. Inoue and M. Kanaoka, "Investigation of electrical Phenomena of Inorganic-filler/LDPE Nanocomposite Material", IEEE Intern. Sympos. Electr. Insulating Materials, P2-31, pp 650-653, 2005.

[15] S. Whitehead, Dielectric Breakdown of Solids, Oxford University Press, London, 1951.

[16] J. J. O'Dwyer, The Theory of Dielectric Breakdown of Solids, Oxford University Press, London, UK, 1964.

[17] Ch. C. Reddy and T. S. Ramu, "On the Computation of Electric Field and Temperature Distribution in HV DC Cable Insulation", IEEE Trans. Dielectr. Electr. Insul, Vol. 13, pp. 1236-44, 2006.

[18] Ch. C. Reddy and T. S. Ramu, "Estimation of Thermal Breakdown Voltage of HVDC Cables - A Theoretical Framework", IEEE Trans. Dielectr. Electr. Insul., Vol.14, pp. 400-408, 2007.

[19] P. C. Irwin, Y. Cao, A. Bansal and L. Schadler, "Thermal and Mechanical Properties of Polyimide Nanocomposites", IEEE Conf. Electr. Insul. Dielectr. Phenomena (CEIDP), pp. 120-123, 2003.

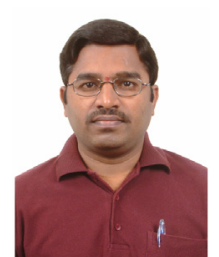

Ch. Chakradhar Reddy was born in Warangal, India, in 1972. He received the B.E (Electrical Engineering.) degree from University College of Engineering (UCE), Osmania University, Hyderabad, India, and the M.E (Electrical Engineering) degree from Indian Institute of Science (IISc), Bangalore, India Currently, he is a research scholar $(\mathrm{PhD})$ in the Department of Electrical Engineering, IISc., India. His research interests include High Voltage and Insulation Engineering, Control Systems and application of Nanotechnology to Power Engineering.

T. S. Ramu was born in Bangalore, India. He received the B.E. degree from Mysore University, Bangalore, India, the M.E. degree from IISc, Bangalore, and the Ph.D. degree from IIT Madras, India.

Currently, he is a Professor in the Department of Electrical Engineering, IISc., India. 